\title{
Prevalence and incidence of hearing impairment among adults: a 13-year follow-up study
}

Venla Lohi†*, Pasi Ohtonen ${ }^{\S}$, Martti Sorri*, Elina Mäki-Torkko*, Samuli Hannula†*

† Department of Otorhinolaryngology and Head and Neck Surgery, Oulu University Hospital, Finland

* PEDEGO Research Unit, University of Oulu, Finland and

Medical Research Centre Oulu, Finland

$\S$ Division of Operative Care and Medical Research Centre Oulu, Oulu University Hospital and University of Oulu, Finland

${ }^{\circ}$ Audiological Research Centre, Faculty of Medicine and Health, Örebro University, Örebro, Sweden Correspondence: $\quad$ Venla Lohi, M.D.

Department of Clinical Medicine, Otorhinolaryngology and PEDEGO research unit, University of Oulu, P.O. Box 5000, FI-90014 University of Oulu, Oulu, Finland.

Fax: +358 8315 3459; E-mail: venla.lohi@oulu.fi

\section{Abstract}

Objective: To investigate the prevalence and incidence of hearing impairment (HI) in a longitudinal setting among adults. Design: An unscreened, population-based epidemiological 13-year follow-up study. Study sample: 850 randomly sampled 54 to 66 -year-old baseline participants, of whom 559 participated in the follow-up study at the age of 68 to 79 years. A questionnaire-based interview, an otological examination and pure-tone audiometry were performed. Results: The overall prevalence of $\mathrm{HI}$ was $70.3 \%$, defined by better ear hearing level $(\mathrm{BEHL}) \geq 20 \mathrm{~dB}$ in the $0.5-4 \mathrm{kHz}$ frequency range. The prevalence was higher among men $(78.6 \%)$ than among women (63.7\%). The overall incidence rate for $\mathrm{HI}$ was 45.8 per 1000 person years and the 13-year cumulative incidence was $60.9 \%$. The incidence was higher among men and older participants. Conclusion: $\mathrm{HI}$ is highly prevalent and incident among older adults in Northern Finland. 


\section{Introduction}

According to WHO estimates, 466 million people are hearing impaired globally (World Health Organization, 2020). Currently, hearing impairment (HI) is estimated to be the most common sensory impairment (Schubert et al., 2017) and one of the leading causes of disability worldwide (Graydon, Waterworth, Miller, \& Gunasekera, 2019). It is known that the prevalence of $\mathrm{HI}$ increases with age (Cruickshanks, K. J., Wiley et al., 1998b; Davis, A., 1995). Furthermore, life expectancy is increasing, and the number of older persons is estimated to increase significantly over the next three decades (The United Nations, 2019). This, together with the high prevalence of $\mathrm{HI}$ among older adults, will lead to a growing disease burden caused by $\mathrm{HI}$. At the individual level, $\mathrm{HI}$ negatively impacts quality of life and psychosocial wellbeing and is associated with cognitive decline, even dementia (Dalton et al., 2003; Deal et al., 2019; Lin, Niparko, \& Ferrucci, 2011; Ray, Popli, \& Fell, 2018).

While cross-sectional studies provide data at a certain time point, longitudinal studies enable the observation of changes in a certain population or a sample. Hearing deteriorates with ageing, and longitudinal studies, in particular, are expected to provide valuable information. On the other hand, longitudinal studies are time consuming and resource intensive. The prevalence of $\mathrm{HI}$ has been reported in several population-based, cross-sectional studies. The National Study of Hearing (NHS) is a comprehensive study reporting the prevalence of HI for different ages (18-80 years) in the UK (Davis, 1995). In the US, the Framingham cohort study, the Epidemiology of Hearing Loss Study (EHLS) and the National Health and Nutrition Survey (NHANES) provide rich and substantial data on HI among adults (Cruickshanks et al., 1998; Gates, Cooper, Kannel, \& Miller, 1990; Goman \& Lin, 2016). The prevalence of HI has also been reported in the Blue Mountains Hearing Study (BMHS) among Australian adults aged 49 years and older (Gopinath et al., 2009) and in a Norwegian study (Borchgrevink, Tambs, \& Hoffman, 2005). More recently, larger studies examining the prevalence of $\mathrm{HI}$ have been conducted in China, the Netherlands and Germany (Homans et al., 2017; von Gablenz, Hoffmann, \& Holube, 2017; Wang et al., 2019). Furthermore, in an older, Finnish 
population-based study, the prevalence of $\mathrm{HI}$ was analysed for different ages from 5 to 75 years (Uimonen, Huttunen, Jounio-Ervasti, \& Sorri, 1999).

However, there are fewer longitudinal studies of $\mathrm{HI}$, especially with larger, well-defined unscreened populations, such as the EHLS, the Framingham Study and the BMHS (Cruickshanks, K. J. et al., 2010; Cruickshanks, Karen J. et al., 2003; Gates \& Cooper, 1991; Mitchell et al., 2011). One longitudinal study has been conducted among a subsample of the NHS population in the UK and another sample from Denmark (Davis, A. C., Ostri, \& Parving, 1990). In that study, it was estimated that average hearing thresholds worsen by $9 \mathrm{~dB}$ over a decade among adults who are 55 years or older. A similar overall rate of deterioration, approximately $1 \mathrm{~dB}$ per year for subjects aged $\geq 60$ years, was reported in another study (Lee, Matthews, Dubno, \& Mills, 2005). Some longitudinal studies in Nordic countries have been conducted in older populations, 70 to 90 -year-olds in Sweden and 70 to 80 -year-olds in Finland showing significant deterioration in hearing even in advanced ages, although these studies had rather small numbers of participants (Hietanen, Era, Sorri, \& Heikkinen, 2004; Jonsson \& Rosenhall, 1998).

We identified only three longitudinal studies reporting incidences of $\mathrm{HI}$ among adults. In the 6-year follow up of Framingham cohort, hearing in $8.4 \%$ of right ears and $13.7 \%$ of left ears worsened to meet the criteria of $\mathrm{HI}$ (pure tone average (PTA) over frequencies $0.5,1,2$ and $4 \mathrm{kHz}$; PTA $0.5-2 \mathrm{kHz}>25 \mathrm{~dB}$ ) (Gates \& Cooper, 1991). In the EHLS, the 5-year cumulative incidence for $\mathrm{HI}$ (worse ear hearing level, $\mathrm{WEHL}_{0.5-4 \mathrm{kHz}}>25 \mathrm{~dB}$ ) was 21.4\% among adults aged 48 to 92 . The cumulative incidence increased markedly with age, being $7.0 \%$ among 48 to 59 -year-old and $45.2 \%$ among 70 to 79 -year-old subjects (Cruickshanks et al., 2003). Furthermore, cumulative incidences of $37.2 \%$ at 10 -year, $54.9 \%$ at 16 -year and $75 \%$ at 20 -year follow-up times have been reported in the EHLS (Cruickshanks et al., 2010; Paulsen et al., 2019; Schubert et al., 2018). In an Australian population, the 5-year incidence for bilateral $\mathrm{HI}$ (PTA $\mathrm{PT}_{0.5-4 \mathrm{kHz}}>25 \mathrm{~dB}$ in the better ear) was 17.9\% (Mitchell et al., 2011).

$\mathrm{HI}$ causes problems at both the population and individual levels. In earlier population-based studies concerning $\mathrm{HI}$ among adults, varying methods and definitions have been used (Roth, Hanebuth, \& Probst, 
2011; Stevens et al., 2013). Differences in the reporting of results make comparison between studies difficult. The epidemiological data on $\mathrm{HI}$ is essential both nationally and globally to estimate the future needs of hearing rehabilitation and to meet the challenge with growing number of hearing impaired adults. Furthermore, biological information concerning age-related conditions, including $\mathrm{HI}$, is needed.

The aim of this study was to investigate the prevalence and incidence of $\mathrm{HI}$ in a population-based sample of older adults in Northern Finland over 13 years.

\section{Participants and methods}

\section{Sample collection}

The baseline study population consisted of 850 adults living in Northern Finland, in or near the City of Oulu, which today has approximately 200000 residents. The area is mostly urban and suburban, including a few rural areas. Subjects were randomly sampled from the population register by their year of birth (between 1938 and 1949) and postal code. The baseline study was performed in conjunction with the European Union ARHI (age-related hearing impairment) project (QLRT-2001-00331) conducted in seven European countries (Van Eyken, Van Camp, \& Van Laer, 2007). The sampling and data collection for the baseline examinations conducted during the period of 2003-2007 have been previously described in detail (Hannula, Mäki-Torkko, Majamaa, \& Sorri, 2010). Sampling of the participants for the follow-up study is shown in Figure 1.

The follow-up study was conducted during the years 2017 and 2018. All participants who had attended the baseline examination were contacted and invited to attend the follow-up study. A total of 749 of 850 (88\%) baseline participants were still alive. Most of them were contacted by telephone. If they agreed to attend, an appointment for clinical examination and hearing tests was scheduled. For those who did not want to participate in the study, a short questionnaire was administered during the phone call. In addition, 62 invitation letters were sent those who were not reached by telephone, including 11 persons who had 
moved, three of whom called back and participated and 16 filled in and returned a short questionnaire for non-responders. Finally, 559 subjects (74.6\%) participated in the follow-up study, 248 men (44.4\%) and 311 women (55.6\%).

- Please place Figure 1. around here -

\section{Data collection}

Before the scheduled appointment, participants received a questionnaire covering their self-perceived hearing problems, ear diseases, general health, noise exposure and possible use of hearing aids. The questionnaire was mostly the same as that used in the baseline examination (Hannula, Bloigu, Majamaa, Sorri, \& Mäki-Torkko, 2011). A few questions that were thought to be irrelevant for the follow-up study were deleted, i.e., questions concerning family history. On the other hand, some questions concerning general health and the use of hearing aids were added. Participants answered the questionnaire at home. The subjects were personally interviewed by one of the researchers (VL) to avoid any misunderstanding of the items in the mailed questionnaire, and when necessary, the medical history was checked from personal medical files. The participants underwent an otological examination by an ENT specialist (VL), including pneumatic otoscopy or otomicroscopy, tympanometry and, for example, ear wax removal when needed.

Pure-tone audiometry was conducted at the Hearing Centre of the Oulu University Hospital with clinical audiometers (Aurical Aud, Otometrics, Denmark) calibrated according to ISO-389-1 (1998). Supra-aural TDH-39 P headphones with MX-41/AR cushions and Radioear NB-71 bone vibrators were used. Pure-tone air conduction thresholds $(0.25,0.5,1,2,3,4,6$ and $8 \mathrm{kHz})$ and bone conduction thresholds $(0.25,0.5,1,2$ and $4 \mathrm{kHz}$ ) were measured by trained audiological assistants in a sound-isolated booth (Puma Pro 45, Puma Soundproofing, Italy) according to the ISO 8253-1 (2010) standard. 


\section{Audiological criteria and definitions}

The average air conduction thresholds (pure tone average, $\mathrm{PTA}_{0.5-4 \mathrm{kHz}}$ ) at frequencies of $0.5,1,2 \mathrm{and} 4 \mathrm{kHz}$ for right and left ears were used to define HI. Better ear hearing level (BEHL) was applied for bilateral HI and worse ear hearing level (WEHL, dB) to include unilateral $\mathrm{HI}$. As recommended by the European expert group (Stephens, 1996; Stevens et al., 2013) and recently by the Global burden of disease expert group on hearing loss (Humes, 2019; Olusanya, Davis, \& Hoffman, 2019), $\mathrm{HI}$ is defined as PTA $\mathrm{P}_{0.5-4 \mathrm{kHz}} \geq 20 \mathrm{~dB}$ in the better ear for bilateral $\mathrm{HI}\left(\mathrm{BEHL}_{0.5-4 \mathrm{kHz}} \geq 20\right.$, hereafter "the EU definition"). Another definition is that of WHO, PTA $0_{0.5-4 \mathrm{kHz}} \geq 26$ in the better ear (WHO, 1991), which has been used in many previous studies (BEHL0.5-4 $\mathrm{kHz}_{2} \geq 26$, hereafter "the WHO definition"). To enable comparison with previous studies, we calculated the prevalence and incidence of $\mathrm{HI}$ using both the $\mathrm{EU}$ and the WHO definitions. Furthermore, $\mathrm{PTA}_{0.5-4 \mathrm{kHz}} \geq 35 \mathrm{~dB}$ was applied as a definition for moderate or worse hearing impairment (Olusanya et al., 2019; Stevens et al., 2013). Cumulative incidence was calculated as the number of new cases of HI during the 13-year follow-up time divided by the total number of individuals in the study population at risk. To estimate the annual incidence, we calculated the sum of the follow-up years for subjects who did not have $\mathrm{HI}$ at the baseline examination, and the incidence rate figures are reported as cases per 1000 person years.

When calculating PTAs, the value of $130 \mathrm{~dB}$ was used if the pure-tone threshold exceeded the maximum output level of the audiometer, as recommended by British Society of Audiology (British Society of Audiology, 1988). If the difference between the left and the right ears was $20 \mathrm{~dB}$ or more for at least two frequencies out of 0.5, 1 and $2 \mathrm{kHz}, \mathrm{HI}$ was considered asymmetrical (Stephens, 1996). Conductive HI was defined as $15 \mathrm{~dB}$ or more difference between air and bone conduction thresholds averaged over $0.5,1$ and $2 \mathrm{kHz}$ frequencies and mixed $\mathrm{HI}$ as a conductive $\mathrm{HI}$ and, in addition, mean bone conduction (over $0.5,1$ and $2 \mathrm{kHz}$ ) $\geq 20 \mathrm{~dB}$ (Stephens, 1996). 
A short questionnaire either by telephone or by mail was completed by 117 (61.6\%) of 190 nonparticipants. The questionnaire covered any self-reported hearing problems, hearing difficulties in background noise, possible use of hearing aids, smoking history and general health issues. The demographics and characteristics of the follow-up study participants and non-participants are presented in Table 1. On average, non-participants were one year older than participants, and the proportion of men was slightly lower among the non-participants. Non-participants were more likely to have $\mathrm{HI}\left(\mathrm{BEHL} \mathrm{L}_{0.5-4}\right.$ $\left.\mathrm{kHz}_{2} \geq 20 \mathrm{~dB}\right)$ at baseline compared to participants $(p=0.038)$. However, they reported fewer self-perceived hearing difficulties. Diabetes was more common among non-participants, but there were no differences in the frequency of cardiovascular conditions.

- Please place Table 1. around here -

\section{Statistical analyses}

IBM SPSS (IBM Corp. Released 2017. IBM SPSS Statistics for Windows, Version 25.0. Armonk, NY: IBM Corp.) software was used for statistical analyses. The chi-squared test was applied to examine sex differences for categorical data. Incidence rates were calculated with $95 \%$ confidence intervals.

\section{Ethical considerations}

This study was approved by the ethical committee of North Ostrobothnia's hospital district according to the guidelines of the Finnish National Advisory Board on Health Care Ethics. Written informed consent was obtained from all the participants. No financial compensation was provided for participation. 


\section{Results}

\section{Prevalence and type of hearing impairment}

Among follow-up participants, the overall prevalence of $\mathrm{HI}$ was $70.3 \%$ according to the EU definition

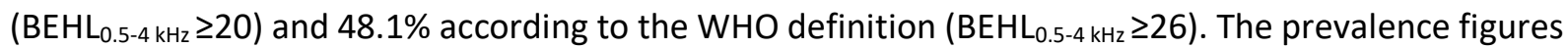
according to sex and different definitions are shown in Table 2. HI was more prevalent among men (78.6\%) than women (63.7\%, according to the EU definition; $\mathrm{p}<0.001)$. Most $(97.2 \%)$ subjects who had $\mathrm{HI}$ at least in either ear (WEHL ${ }_{0.5-4} \mathrm{kHz} \geq 20 \mathrm{~dB} \mathrm{HL}$ ) had sensorineural HI. Thirteen subjects had mixed $\mathrm{HI}$ ( $2.3 \%$ of all subjects). Thirty-nine (7.0\%) subjects had asymmetrical HI (eleven of them mixed type), and 28 (5.0\%) subjects had asymmetrical sensorineural HI.

- Please place Table 2. around here -

\section{Incidence of hearing impairment}

The mean follow-up time was 13.3 years (median 13.0 years, SD 0.56 years, range 12 to 16 years). To define the incidence of $\mathrm{HI}$, we analysed individuals who did not have $\mathrm{HI}$ at the baseline examination who attended the follow-up study. When using the EU criteria, there were 425 participants at risk for bilateral $\mathrm{HI}\left(\mathrm{BEHL}_{0.5-4}\right.$ $\mathrm{kHz}_{2}<20$ ) and 345 participants at risk for uni- or bilateral $\mathrm{HI}\left(\mathrm{WEHL}_{0.5-4 \mathrm{kHz}}<20\right)$. In the follow-up examination,

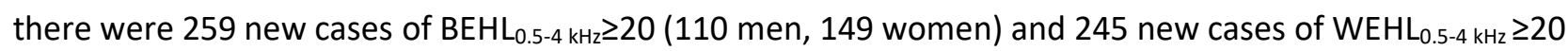
(97 men, 148 women). For the WHO criteria, 490 participants were at risk according to BEHL (BEHL $0.5-4$ $\mathrm{kHz}_{2}<26$ and 429 participants according to WEHL (WEHL $\left.\mathrm{L}_{0.5-4 \mathrm{kHz}}<26\right)$ at baseline. In the follow-up examination, there were 200 new cases for $\mathrm{BEHL}_{0.5-4 \mathrm{kHz}} \geq 26$ (100 men, 100 women) and 239 new cases for $\mathrm{WEHL}_{0.5-4 \mathrm{kHz}} \geq 26$ (105 men, 134 women). For at least moderate $\mathrm{HI}$, there were 115 new cases ( 66 men, 49 women) among

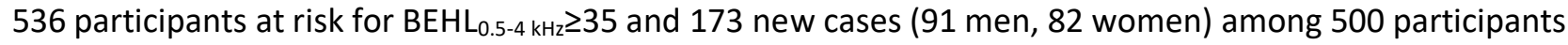
at risk for $\mathrm{WEHL}_{0.5-4 \mathrm{kHz}} \geq 35$. We calculated the 13 -year cumulative incidences as well as the incidence rates 
per person years in two baseline age groups as 54-60 years and 61-66 years, respectively. In general, the incidence figures were higher in both age groups among men than among women. For the EU definition, the sex difference was smaller in the older age group. The 13-year cumulative incidences and the incidence rates by age and sex are shown in Table 3 for the better ear and in Table 4 for the worse ear.

- Please place Table 3. and Table 4. around here-

\section{Discussion}

During the 13-year follow-up, the overall prevalence of $\mathrm{HI}$ ( $B E H L_{0.5-4} \mathrm{kHz} \geq 20 \mathrm{~dB}$ ) increased from $26.7 \%$ to 70.3\%. At follow-up, $\mathrm{HI}$ was present in $60.9 \%$ of participants who did not have $\mathrm{HI}$ at baseline. The overall prevalence of at least moderate $\mathrm{HI}$ (BEHL $0.5-4 \mathrm{kHz} \geq 35 \mathrm{~dB}$ ) increased from $4.9 \%$ to $24.7 \%$.

For comparison with previous studies, we chose the nearest eligible age group and definition. In the NHS, prevalence for $\mathrm{HI}$, defined as $\mathrm{BEHL}_{0.5-4 \mathrm{kHz}} \geq 20 \mathrm{~dB}$, was slightly higher (74.0\%) with a small difference in the age distribution (Davis, 1995). When using the criteria of $\geq 35 \mathrm{~dB}$ for $\mathrm{HI}$, the prevalence was $25.5 \%$ among 61- to 80 -year-olds in the NHS study (Davis, 1995), which is similar to the prevalence of $24.7 \%$ in our study. The prevalence figures in the NHANES data collected from 2001 to 2008 are very similar to our results in the age group of 70 to 79 years (Lin et al., 2011). Our prevalence results are also comparable with the Norwegian prevalence of $64 \%$ among men and $45 \%$ among women aged $70-74$ years (Borchgrevink et al., 2005). The $66 \%$ prevalence of $\mathrm{HI}$ in the EHLS, defined by $\mathrm{WEHL}_{0.5-4 \mathrm{kHz}} \geq 25 \mathrm{~dB}$, is also similar to the results of the present study.

There are recent studies suggesting that the age-adjusted prevalence of $\mathrm{HI}$ has decreased. In a Swedish cohort comparison among 70-year-old persons, the prevalence of $\mathrm{HI}$ ( $\mathrm{BEHL} \mathrm{L}_{0.5-4 \mathrm{kHz}} \geq 25 \mathrm{~dB}$ ) decreased from 53 to $28 \%$ among men and from 37 to $23 \%$ among women in four decades (Hoff, Tengstrand, Sadeghi, Skoog, \& Rosenhall, 2018). The authors speculate that the reason for this could be a reduction in noise-induced hearing loss. Similar results of decreasing prevalence of $\mathrm{HI}$ during the last decades have been found in the 
NHANES, the EHLS and in the Norwegian HUNT study, indicating that modifiable risk factors might influence the development of HI (Hoffman, Dobie, Losonczy, Themann, \& Flamme, 2017; Zhan et al., 2010; Engdahl, Strand and Aarhus 2020). When comparing our results to earlier studies in Finland, the prevalence of HI $\left(B E H L_{0.5-4 \mathrm{kHz}} \geq 20 \mathrm{~dB}\right.$ ) in our study population is actually lower than in the study of Hietanen et al (2005) among 75-year-old persons examined nearly twenty years earlier in Finland, Sweden and Denmark. In that study, the prevalence of $\mathrm{HI}\left(\mathrm{BEHL}_{0.5-4 \mathrm{kHz}}>20 \mathrm{~dB}\right.$ ) was 79.2-92.1\% among men and 66.1-75.6\% among women (Hietanen et al., 2005). In another population-based Finnish study from the 1990s, the overall prevalence among 75 -year-old population was lower $\left(64.5 \%, \mathrm{BEHL}_{0.5-4 \mathrm{kHz}} \geq 20 \mathrm{~dB}\right.$ ) than in the present study (Uimonen et al., 1999). That earlier study was also conducted in Northern Finland and thus might be more comparable to the present study. However, in that earlier study, all participants were 75 years old, while in the present study, the age range was wider. Furthermore, the proportion of women was larger in the study of Uimonen and co-workers. Taken together, based on the results of the present and previous Finnish studies, any conclusion of decreasing prevalence of $\mathrm{HI}$ in Finland cannot be drawn.

In the current study, the incidence of $\mathrm{HI}$ was found to be higher among men than women. This was the case especially among the younger participants, where the 13-year cumulative incidence was $56.4 \%$ among men and $41.0 \%$ among women, according to the EU definition. The difference was clearly smaller among the older men (77.6\%) and women, (73.4\%). This supports the findings that $\mathrm{HI}$ affects men earlier than women, as shown in previous studies (Cruickshanks et al., 2010; Pearson et al., 1995). In contrast, no significant sex differences in the incident hearing loss was observed in the BMHS (Mitchell et al., 2011). In the 15-year follow-up of the EHLS, 835 new cases of HI were reported among 1925 subjects at risk (43.4\%), which is clearly lower than in our study (57.6\%) (Cruickshanks, Karen J. et al., 2015). One plausible explanation is that in the EHLS, HI was more prevalent at baseline $\left(\mathrm{WEHL}_{0.5-4 \mathrm{kHz}}>25\right)$ than in our study $(45.9 \%$ vs. $25.4 \%$, respectively) (Cruickshanks, K. J. et al., 1998a). Furthermore, there are differences in the age distributions between our study and the EHLS. 
In the present study, incidence rates calculated per person years enable the comparison of incidences independent of follow-up time. Nevertheless, it was difficult to find any comparable study reporting person-year incidence rates for HI. A South Korean epidemiological study on the association of diabetes and incident hearing loss reports an incidence rate of hearing loss 1.8 per 1000 person years among participants (mean age 37.6 years) with normal glucose levels and corresponding figures for participants with pre-diabetes and diabetes (3.1 and 9.2 per 1000 person years, respectively) (Kim et al., 2017). It is understandable that these figures are not comparable to our results due to the selected disease and younger population. Nevertheless, it is obvious that the incidence of $\mathrm{HI}$ is increasing markedly by age. The incidence rate of $\mathrm{HI}$ (BEHL $\mathrm{B}_{0.5-4 \mathrm{kHz}} \geq 20,45.8$ per 1000 person years) is high also when compared to other public health problems. For example, the incidence of type 2 diabetes in corresponding age group has been reported to be 16 per 1000 person years and the overall age-standardized incidence rate of cardiovascular disease was 22.5 per 1000 person years in the NHANES (Ergin, Muntner, Sherwin, \& He, 2004; Nichols et al., 2015). To obtain comparable results, similar definitions and standardized protocols should be used in epidemiological studies concerning $\mathrm{HI}$ among adults. This concern has been voice by other researchers as well (Roth et al., 2011).

Our study has several strengths. This study adds comparable information to the body of current knowledge about the epidemiology of hearing impairment. The population-based longitudinal setting with good adherence increases the reliability of our results. For follow-up examination, even though it was timeconsuming, we chose to invite the subjects by a personal telephone call from one of the researchers (VL) to reach as many participants as possible. The study protocol was similar at baseline and follow-up examinations. Proper and standardized audiometric measurements were conducted by a limited number (three) of trained audiology assistants in the follow-up examination to reduce the variability in examination procedures. In addition, all clinical examinations and interviews were conducted by the same person (VL).

Of course, there are also some limitations in this study. Our results come from a restricted area in Finland, and any generalization should be performed with caution. Selection bias is possible as well, since 
participants reported hearing difficulties more often than non-participants and may have been more eager to participate for this reason, resulting in over-estimated prevalence and incidence figures. However, the figures could also be underestimated, as analysis of non-participants showed that they were more likely to have $\mathrm{HI}$ at the baseline examination than the participants. On the other hand, a larger proportion of nonparticipants (19.7\%) than participants (14.9\%) were already using hearing aids; therefore, they might not have been interested in participating. Home visits and portable audiometers could have resulted in better attendance, as many of the non-participants might have been willing to attend if those had been provided. However, the quality of audiometric results would not have been as good as with proper clinical audiometry conducted at the study appointment. According to the instructions given by the Ethical Committee of North Ostrobothnia's Hospital District, the reasons for non-participation could not be investigated. However, many of the contacted non-participants spontaneously reported health-related issues, were caring for a significant other or had difficulties getting to the Hearing Centre when no compensation for travel was available.

\section{Conclusions}

Our results indicate a high prevalence and incidence of $\mathrm{HI}$ among older adults. At the follow-up examination, nearly $80 \%$ of men and over $60 \%$ of women had at least mild HI. Nearly one in three men and one in five women exhibited moderate or worse $\mathrm{HI}$. The incidence of $\mathrm{HI}$ was higher among men than among women, especially among younger participants, indicating that men develop $\mathrm{HI}$ earlier than women. Our results strengthen the previous understanding that $\mathrm{HI}$ is an important public health issue among older adults. The results of this study are valuable for making decisions on hearing health care.

\section{Acknowledgements}


We are grateful to all the study participants. We would like to thank the audiology assistants who were working for this project and the staff of the Hearing Centre at the Oulu University Hospital.

Funding

This work was supported by Finnish State Research funding and grants from the Yrjö Jahnsson Foundation, Päivikki and Sakari Sohlberg Foundation and the Finnish Society of Audiology.

Disclosure statement

The authors report no conflicts of interest. All responsibility for the content and writing of the paper is taken by the authors alone. 


\section{References}

Borchgrevink H.M., Tambs K. \& Hoffman H.J. 2005. The Nord-Trondelag Norway Audiometric Survey 199698: unscreened thresholds and prevalence of hearing impairment for adults $>20$ years. Noise \& Health, 7, 1-15.

British Society of Audiology (1988). British Society of Audiology recommendation. Descriptors for pure-tone audiograms. British Journal of Audiology, 22:2, 123. http://dx.doi.org/10.3109/03005368809077807

Cruickshanks, K. J., Klein, R., Klein, B. E., Wiley, T. L., Nondahl, D. M., \& Tweed, T. S. (1998a). Cigarette smoking and hearing loss: The epidemiology of hearing loss study. Jama, 279(21), 1715-1719.

Cruickshanks, K. J., Nondahl, D. M., Tweed, T. S., Wiley, T. L., Klein, B. E., Klein, R. \&Nash, S. D. (2010). Education, occupation, noise exposure history and the 10-yr cumulative incidence of hearing impairment in older adults. Hearing Research, 264(1-2), 3-9. doi: http://dx.doi.org/10.1016/j.heares.2009.10.008

Cruickshanks, K. J., Wiley, T. L., Tweed, T. S., Klein, B. E., Klein, R., Mares-Perlman, J. A., \& Nondahl, D. M. (1998b). Prevalence of hearing loss in older adults in beaver dam, Wisconsin. The epidemiology of hearing loss study. American Journal of Epidemiology, 148(9), 879-886.

Cruickshanks, K. J., Nondahl, D. M., Dalton, D. S., Fischer, M. E., Klein, B. E. K., Klein, R. \& Tweed, T. S. (2015). Smoking, central adiposity, and poor glycemic control increase risk of hearing impairment. Journal of the American Geriatrics Society, 63(5), 918-924.

Cruickshanks, K. J., Tweed, T. S., Wiley, T. L., Klein, B. E. K., Klein, R., Chappell, R. \& Dalton, D. S. (2003). The 5 -year incidence and progression of hearing loss: The epidemiology of hearing loss study. Archives of Otolaryngology -- Head \& Neck Surgery, 129(10), 1041-1046.

Dalton, D. S., Cruickshanks, K. J., Klein, B. E. K., Klein, R., Wiley, T. L., \& Nondahl, D. M. (2003). The impact of hearing loss on quality of life in older adults. Gerontologist, 43(5), 661-668.

Davis, A. C., Ostri, B., \& Parving, A. (1990). Longitudinal study of hearing. Acta Oto-Laryngologica Supplement, 476, 12-22.

Davis, A. C. (ed., 1995). Hearing in adults. Whurr Publishers Ltd. London

Deal, J. A., Reed, N. S., Kravetz, A. D., Weinreich, H., Yeh, C., Lin, F. R., \& Altan, A. (2019). Incident hearing loss and comorbidity: A longitudinal administrative claims study. JAMA Otolaryngology-- Head \& Neck Surgery, 145(1), 36-43. doi: https://dx.doi.org/10.1001/jamaoto.2018.2876

Engdahl B., Strand B.H. \& Aarhus L. (2020). Better Hearing in Norway: A Comparison of Two HUNT Cohorts 20 Years Apart. Ear Hear.

Ergin, A., Muntner, P., Sherwin, R., \& He, J. (2004). Secular trends in cardiovascular disease mortality, incidence, and case fatality rates in adults in the united states. American Journal of Medicine, 117(4), 219227.

Gates, G. A., \& Cooper, J. C. (1991). Incidence of hearing decline in the elderly. Acta Oto-Laryngologica, $111(2), 240-248$.

Gates, G. A., Cooper, J. C.,Jr, Kannel, W. B., \& Miller, N. J. (1990). Hearing in the elderly: The Framingham cohort, 1983-1985. Part I. Basic audiometric test results. Ear \& Hearing, 11(4), 247-256. 
Goman A.M. \& Lin F.R. (2016). Prevalence of Hearing Loss by Severity in the United States. Am J Public Health, 106, 1820-1822.

Gopinath, B., Rochtchina, E., Wang, J. J., Schneider, J., Leeder, S. R., \& Mitchell, P. (2009). Prevalence of agerelated hearing loss in older adults: Blue mountains study. Archives of Internal Medicine, 169(4), 415-416.

Graydon, K., Waterworth, C., Miller, H., \& Gunasekera, H. (2019). Global burden of hearing impairment and ear disease. Journal of Laryngology \& Otology, 133(1), 18-25. doi:

https://dx.doi.org/10.1017/S0022215118001275

Hannula, S., Bloigu, R., Majamaa, K., Sorri, M., \& Mäki-Torkko, E. (2011). Audiogram configurations among older adults: Prevalence and relation to self-reported hearing problems. International Journal of Audiology, 50(11), 793-801. doi:10.3109/14992027.2011.593562

Hannula, S., Mäki-Torkko, E., Majamaa, K., \& Sorri, M. (2010). Hearing in a 54- to 66-year-old population in northern finland. International Journal of Audiology, 49(12), 920-927. doi: 10.3109/14992027.2010.510146

Hietanen, A., Era, P., Henrichsen, J., Rosenhall, U., Sorri, M., \& Heikkinen, E. (2005). Hearing among 75-yearold people in three nordic localities: A comparative study. International Journal of Audiology, 44(9), 500508.

Hietanen, A., Era, P., Sorri, M., \& Heikkinen, E. (2004). Changes in hearing in 80-year-old people: A 10-year follow-up study. International Journal of Audiology, 43(3), 126-135.

Hoff, M., Tengstrand, T., Sadeghi, A., Skoog, I., \& Rosenhall, U. (2018). Improved hearing in Swedish 70-year olds-a cohort comparison over more than four decades (1971-2014). Age \& Ageing, 47(3), 437-444.

Hoffman, H. J., Dobie, R. A., Losonczy, K. G., Themann, C. L., \& Flamme, G. A. (2017). Declining prevalence of hearing loss in US adults aged 20 to 69 years. JAMA Otolaryngology-- Head \& Neck Surgery, 143(3), 274285.

Homans N.C., Metselaar R.M., Dingemanse J.G., van der Schroeff M.P., Brocaar M.P., et al. 2017. Prevalence of age-related hearing loss, including sex differences, in older adults in a large cohort study. Laryngoscope, 127, 725-730.

Humes, L. E. (2019). The world health organization's hearing-impairment grading system: An evaluation for unaided communication in age-related hearing loss. International Journal of Audiology, 58(1), 12-20.

International Organization for Standardization. ISO 8253-1:2010 Audiometric test methods - Part 1: Puretone air and bone conduction audiometry.

Jonsson, R., \& Rosenhall, U. (1998). Hearing in advanced age. A study of presbyacusis in 85-, 88- and 90year-old people. Audiology, 37(4), 207-218.

Kim, M., Zhang, Y., Chang, Y., Ryu, S., Choi, Y., Kwon, M., \& Cho, J. (2017). Diabetes mellitus and the incidence of hearing loss: A cohort study. International Journal of Epidemiology, 46(2), 717-726. doi: https://dx.doi.org/10.1093/ije/dyw243

Lee, F. S., Matthews, L. J., Dubno, J. R., \& Mills, J. H. (2005). Longitudinal study of pure-tone thresholds in older persons. Ear \& Hearing, 26(1), 1-11.

Lin, F. R., Niparko, J. K., \& Ferrucci, L. (2011). Hearing loss prevalence in the united states. Archives of Internal Medicine, 171(20), 1851-1852. 
Mitchell, P., Gopinath, B., Wang, J. J., McMahon, C. M., Schneider, J., Rochtchina, E., \& Leeder, S. R. (2011). Five-year incidence and progression of hearing impairment in an older population. Ear \& Hearing, 32(2), 251-257. doi: https://dx.doi.org/10.1097/AUD.0b013e3181fc98bd

Nichols, G. A., Schroeder, E. B., Karter, A. J., Gregg, E. W., Desai, J., Lawrence, J. M., \& SUPREME-DM Study Group. (2015). Trends in diabetes incidence among 7 million insured adults, 2006-2011: The SUPREME-DM project. American Journal of Epidemiology, 181(1), 32-39.

Olusanya, B. O., Davis, A. C., \& Hoffman, H. J. (2019). Hearing loss grades and the international classification of functioning, disability and health. Bulletin of the World Health Organization, 97(10), 725-728. doi:https://dx.doi.org/10.2471/BLT.19.230367

Paulsen, A. J., Cruickshanks, K. J., Pinto, A., Schubert, C. R., Dalton, D. S., Fischer, M. E. \& Tweed, T. S. (2019). Neuroprotective factors and incident hearing impairment in the epidemiology of hearing loss study. Laryngoscope, 129(9), 2178-2183.

Pearson, J. D., Morrell, C. H., Gordon-Salant, S., Brant, L. J., Metter, E. J., Klein, L. L., \& Fozard, J. L. (1995). Gender differences in a longitudinal study of age-associated hearing loss. Journal of the Acoustical Society of America, 97(2), 1196-1205.

Ray, J., Popli, G., \& Fell, G. (2018). Association of cognition and age-related hearing impairment in the english longitudinal study of ageing. JAMA Otolaryngology-- Head \& Neck Surgery, 144(10), 876-882.

Roth, T. N., Hanebuth, D., \& Probst, R. (2011). Prevalence of age-related hearing loss in europe: A review. European Archives of Oto-Rhino-Laryngology, 268(8), 1101-1107. doi: https://dx.doi.org/10.1007/s00405011-1597-8

Schubert, C. R., Cruickshanks, K. J., Fischer, M. E., Chen, Y., Klein, B. E. K., Klein, R., \& Pinto, A. A. (2017). Sensory impairments and cognitive function in middle-aged adults. Journals of Gerontology Series ABiological Sciences \& Medical Sciences, 72(8), 1087-1090. doi: https://dx.doi.org/10.1093/gerona/glx067

Schubert, C. R., Paulsen, A. J., Nondahl, D. M., Dalton, D. S., Fischer, M. E., Klein, B. E. K.\& Cruickshanks, K. J. (2018). Association between cystatin C and 20-year cumulative incidence of hearing impairment in the epidemiology of hearing loss study. 06 01: doi: https://dx.doi.org/10.1001/jamaoto.2018.0041

Stephens, D. (1996). Study group on terminology, definitions and hearing assessment. In A. Martini (Ed.), European work group on genetics of hearing impairment. European commission directorate, biomedical and health research program (HEAR) info letter 2, (November 1996, 8 ed.)

Stevens, G., Flaxman, S., Brunskill, E., Mascarenhas, M., Mathers, C. D., Finucane, M., \& Global Burden of Disease Hearing Loss Expert Group. (2013). Global and regional hearing impairment prevalence: An analysis of 42 studies in 29 countries. European Journal of Public Health, 23(1), 146-152.

The United Nations. (2019). World population prospects. Retrieved from https://population.un.org/wpp/Publications/Files/WPP2019_Highlights.pdf

Uimonen, S., Huttunen, K., Jounio-Ervasti, K., \& Sorri, M. (1999). Do we know the real need for hearing rehabilitation at the population level? Hearing impairments in the 5- to 75-year-old cross-sectional Finnish population. British Journal of Audiology, 33(1), 53-59.

Van Eyken, E., Van Camp, G., \& Van Laer, L. (2007). The complexity of age-related hearing impairment: Contributing environmental and genetic factors. Audiology \& Neuro-Otology, 12(6), 345-358. 
von Gablenz, P., Hoffmann, E., \& Holube, I. (2017). Prevalence of hearing loss in northern and southern germany. [Pravalenz von Schwerhorigkeit in Nord- und Sud-Deutschland.] Hno, 65(Suppl 2), 130-135. doi:https://dx.doi.org/10.1007/s00106-016-0318-4

Wang, D., Zhang, H., Ma, H., Zhang, L., Yang, L., \& Xu, L. (2019). Hearing threshold levels and hearing loss among people in zhejiang, china: A population-based cross-sectional study. BMJ Open, 9(4), e027152. doi:https://dx.doi.org/10.1136/bmjopen-2018-027152

World Health Organization (1991). "Report of the Informal Working Group on Prevention of Deafness and Hearing Impairment: Programme Planning. WHO/PDH/91.1." Geneva, Switzerland: WHO.

World Health Organization (2020). https://www.who.int/news-room/fact-sheets/detail/deafness-andhearing-loss

Zhan, W., Cruickshanks, K. J., Klein, B. E. K., Klein, R., Huang, G., Pankow, J. S. \& Tweed, T. S. (2010). Generational differences in the prevalence of hearing impairment in older adults. American Journal of Epidemiology, 171(2), 260-266. doi: https://dx.doi.org/10.1093/aje/kwp370 
Table 1. The comparison of characteristics of the study participants and non-participants in the 13-year follow-up study. Responders refer to non-participants, who responded a short query.

\begin{tabular}{|c|c|c|c|c|}
\hline & \multirow{3}{*}{$\begin{array}{l}\text { Baseline } \\
(n=850)\end{array}$} & \multicolumn{3}{|c|}{ Follow-up } \\
\hline & & \multirow[t]{2}{*}{ Participants $(N=559)$} & \multicolumn{2}{|c|}{ Non-participants $(N=190)$} \\
\hline & & & $\begin{array}{l}\text { Responders } \\
\quad(N=117)\end{array}$ & $\begin{array}{l}\text { Non- } \\
\text { responders } \\
(N=73)\end{array}$ \\
\hline Men, $N(\%)$ & $383(45.1)$ & $248(44.4)$ & $50(42.7)$ & $28(38.4)$ \\
\hline Age range, years & $54-66$ & $67-79$ & $68-79$ & $68-80$ \\
\hline Mean age, years (SD) & $61.0(3.4)$ & 73.9 (3.3) & 74.9 (3.6) & $74.4(3.4)$ \\
\hline Median age, years & 62.0 & 74.0 & 77.0 & 75.0 \\
\hline 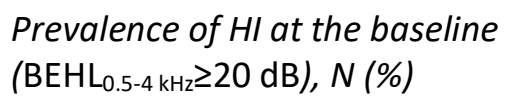 & $227(26.7)^{b}$ & $134(24.0)$ & $32(27.4)$ & $25(34.2)$ \\
\hline $\begin{array}{l}\text { Self-reported hearing difficulty }{ }^{a} \text {, } \\
N(\%)\end{array}$ & $315(37.1)^{b}$ & $260(46.9)$ & $37(31.6)$ & - \\
\hline use of hearing aid, $N(\%)$ & $\begin{array}{c}\text { (not } \\
\text { available) }\end{array}$ & $83(14.9)$ & $23(19.7)$ & - \\
\hline History of smoking, $N(\%)$ & $314(36.9)^{b}$ & $204(36.5)$ & $40(35.1)^{c}$ & - \\
\hline $\begin{array}{l}\text { Any cardiovascular condition }{ }^{d}, \\
N(\%)\end{array}$ & $415(48.8)$ & $373(66.4)$ & $71(62.3)^{c}$ & - \\
\hline Diabetes, $N(\%)$ & $77(9.1)$ & $98(17.7)$ & $31(27.7)^{\mathrm{e}}$ & - \\
\hline
\end{tabular}

a answered "yes" to the question: "Do you have any difficulty with your hearing?"

${ }^{b}$ previously reported data (Hannula et al., 2010; Hannula et al. 2011)

${ }^{c}$ data available for 114 non-participants

${ }^{d}$ hypertension, ischemic heart disease, heart attack, atrial fibrillation, valve problem, heart insufficiency, intermittent claudication, or history of stroke

${ }^{\mathrm{e}}$ data available for 112 non-participants 
Table 2.

Prevalence of hearing impairment (HI) in the baseline ${ }^{\mathrm{a}}(\mathrm{n}=850$, mean age 61.0 years) and follow-up examinations ( $\mathrm{n}=559$, mean age 73.9 years) according to different definitions, sex and participance. $\mathrm{HI}$ is defined as pure-tone average of $\geq 20 \mathrm{~dB}, \geq 26 \mathrm{~dB}$ and $\geq 35 \mathrm{~dB}$ at the frequencies of $0.5,1,2$ and $4 \mathrm{kHz}$ in the better ear (BEHL) and worse ear (WEHL). $\chi^{2}$-test was applied for sex differences $(\mathrm{P}<0.001)$.

\begin{tabular}{|c|c|c|c|c|c|c|}
\hline \multirow[b]{4}{*}{ Definition of $\mathrm{HI}$} & \multicolumn{6}{|c|}{ Study group } \\
\hline & \multicolumn{4}{|c|}{ Baseline } & \multirow{2}{*}{\multicolumn{2}{|c|}{$\begin{array}{c}\text { Follow-up } \\
N=559\end{array}$}} \\
\hline & \multicolumn{2}{|c|}{$\begin{array}{c}A l l \\
N=850\end{array}$} & \multicolumn{2}{|c|}{$\begin{array}{l}\text { Follow-up participants } \\
\qquad N=559\end{array}$} & & \\
\hline & $\begin{array}{c}\text { Men } \\
N=383\end{array}$ & $\begin{array}{l}\text { Women } \\
N=467\end{array}$ & $\begin{array}{c}\text { Men } \\
N=248\end{array}$ & $\begin{array}{l}\text { Women } \\
N=311\end{array}$ & $\begin{array}{c}\text { Men } \\
N=248\end{array}$ & $\begin{array}{l}\text { Women } \\
N=311\end{array}$ \\
\hline $\mathrm{BEHL} \geq 20, n(\%)$ & $141(36.8)^{\mathrm{a}}$ & $86(18.4)^{a}$ & $85(34.3)$ & 49 (15.8) & $195(78.6)$ & $198(63.7)$ \\
\hline WEHL $\geq 20, n(\%)$ & $206(53.8)^{\mathrm{a}}$ & $153(32.8)^{\mathrm{a}}$ & $125(50.4)$ & $89(28.6)$ & 222 (89.5) & $236(75.9)$ \\
\hline$B E H L \geq 26, n(\%)$ & $73(19.1)$ & $43(9.2)$ & $41(16.5)$ & $28(9.0)$ & 141 (56.9) & $128(41.2)$ \\
\hline WEHL $\geq 26, n(\%)$ & $136(35.5)$ & $80(17.1)$ & $82(33.1)$ & $48(15.4)$ & $187(75.4)$ & $182(58.5)$ \\
\hline BEHL $\geq 35, n(\%)$ & $27(7.0)$ & $15(3.2)$ & $14(5.6)$ & $9(2.9)$ & $80(32.3)$ & $58(18.6)$ \\
\hline WEHL $\geq 35, n(\%)$ & 64 (16.7) & $34(7.3)$ & 39 (15.7) & $20(6.4)$ & $130(52.4)$ & $102(32.8)$ \\
\hline
\end{tabular}

a Previously published (Hannula et al., 2010) 
Table 3. Better ear incidence rates and 13-year cumulative incidences of hearing impairment $(\mathrm{HI})$ in the study population ( $\mathrm{N}=559)$ according to age at baseline and sex. $\mathrm{HI}$ is defined as $\geq 20, \geq 26$ or $\geq 35 \mathrm{~dB}$ better ear hearing level (BEHL) at $0.5,1,2$ and $4 \mathrm{kHz}$.

\begin{tabular}{|c|c|c|c|c|c|c|c|c|c|c|}
\hline $\begin{array}{l}\text { Age } \\
\text { group }\end{array}$ & Sex & \multicolumn{3}{|c|}{$B E H L \geq 20 d B$} & \multicolumn{3}{|c|}{$B E H L \geq 26 d B$} & \multicolumn{3}{|c|}{$B E H L \geq 35 d B$} \\
\hline \multirow[t]{3}{*}{$54-60$} & Men & 1038 & 42.4 (30.8 to 52.9$)$ & 56.4 & 1278 & 28.2 (19.7 to 39.0$)$ & 37.5 & 1359 & 15.5 (9.6 to 23.6$)$ & 20.6 \\
\hline & Women & 1789 & $30.7(23.2$ to 40.0$)$ & 41.0 & 1923 & 19.8 (14.0 to 27.1$)$ & 26.6 & 1990 & 7.5 (4.2 to 12.4 ) & 10.1 \\
\hline & All & 2827 & $35.0(28.5$ to 42.6$)$ & 46.7 & 3201 & 23.1 (18.2 to 29.0$)$ & 31.0 & 3349 & 10.7 (7.5 to 14.9$)$ & 14.4 \\
\hline \multirow[t]{3}{*}{$61-66$} & Men & 1134 & 58.2 (45.0 to 74.0$)$ & 77.6 & 1464 & 43.7 (33.7 to 55.8 ) & 57.7 & 1741 & 25.8 (18.9 to 34.6$)$ & 34.1 \\
\hline & Women & 1697 & 55.4 (44.8 to 67.8$)$ & 73.4 & 1855 & 33.4 (25.6 to 42.8$)$ & 44.3 & 2041 & 16.7 (11.5 to 23.3$)$ & 22.1 \\
\hline & All & 2831 & 56.5 (48.1 to 66.0$)$ & 75.1 & 3319 & 38.0 (31.6 to 45.2$)$ & 50.2 & 3782 & 20.9 (16.5 to 26.0$)$ & 27.6 \\
\hline \multirow[t]{3}{*}{$A / l$} & Men & 2172 & $50.6(41.6$ to 61.1$)$ & 67.5 & 2742 & $36.5(29.7$ to 44.4$)$ & 48.3 & 3100 & 21.3 (16.5 to 27.1$)$ & 28.2 \\
\hline & Women & 3486 & $42.7(36.2$ to 50.2$)$ & 56.9 & 3778 & 26.5 (21.5 to 32.2$)$ & 35.3 & 4031 & 12.2 (9.0 to 16.1$)$ & 16.2 \\
\hline & $A / l$ & 5658 & 45.8 (40.4 to 51.7$)$ & 60.9 & 6520 & 30.7 (26.6 to 35.2 ) & 40.8 & 7131 & 16.1 (13.3 to 19.4$)$ & 21.5 \\
\hline
\end{tabular}


Table 4. Worse ear incidence rates and 13-year cumulative incidences of hearing impairment ( $\mathrm{HI})$ in the study population ( $\mathrm{N}=559)$ according to age at baseline and sex. $\mathrm{HI}$ is defined as $\geq 20, \geq 26$ or $\geq 35 \mathrm{~dB}$ worse ear hearing level (WEHL) at $0.5,1,2$ and $4 \mathrm{kHz}$.

\begin{tabular}{|c|c|c|c|c|c|c|c|c|c|c|}
\hline \multirow[b]{2}{*}{$\begin{array}{l}\text { Age } \\
\text { group }\end{array}$} & \multirow[b]{2}{*}{ Sex } & \multicolumn{3}{|c|}{$W E H L \geq 20 d B$} & \multicolumn{3}{|c|}{$W E H L \geq 26 d B$} & \multicolumn{3}{|c|}{$W E H L \geq 35 d B$} \\
\hline & & $\begin{array}{c}\text { Person } \\
\text { years }\end{array}$ & $\begin{array}{c}\text { Incidence rate } \\
(95 \% \mathrm{Cl})\end{array}$ & $\begin{array}{c}\text { Cumulative } \\
\text { incidence, } \\
\%\end{array}$ & $\begin{array}{l}\text { Person } \\
\text { years }\end{array}$ & $\begin{array}{c}\text { Incidence rate } \\
(95 \% \mathrm{Cl})\end{array}$ & $\begin{array}{l}\text { Cumulative } \\
\text { incidence, \% }\end{array}$ & $\begin{array}{c}\text { Person } \\
\text { years }\end{array}$ & $\begin{array}{c}\text { Incidence rate } \\
(95 \% \mathrm{CI})\end{array}$ & $\begin{array}{l}\text { Cumulative } \\
\text { incidence, } \%\end{array}$ \\
\hline \multirow[t]{3}{*}{$54-60$} & Men & 786 & 53.4 (38.5 to 72.2$)$ & 71.2 & 1078 & 44.5 (32.8 to 59.0$)$ & 59.3 & 1238 & 28.3 (19.7 to 39.3 ) & 37.6 \\
\hline & Women & 1573 & 42.6 (33.0 to 54.1$)$ & 56.8 & 1829 & 29.5 (22.2 to 38.5$)$ & 39.7 & 1934 & 14.5 (9.6 to 20.9 ) & 19.4 \\
\hline & $A / l$ & 2359 & 46.2 (37.9 to 55.8 ) & 61.6 & 2907 & 35.1 (28.6 to 42.6$)$ & 47.0 & 3172 & 19.9 (15.3 to 25.4 ) & 26.6 \\
\hline \multirow[t]{3}{*}{$61-66$} & Men & 853 & 64.5 (48.6 to 83.9 ) & 85.9 & 1119 & 50.9 (38.6 to 66.0$)$ & 67.1 & 1528 & 36.6 (27.7 to 47.6$)$ & 48.3 \\
\hline & Women & 1381 & 58.7 (46.6 to 72.9 ) & 77.9 & 1683 & 47.5 (37.7 to 59.2 ) & 63.0 & 1947 & 27.7 (20.8 to 36.2 ) & 36.7 \\
\hline & $A / l$ & 2234 & 60.9 (51.1 to 72.0$)$ & 81.0 & 2802 & 48.9 (41.0 to 57.8$)$ & 64.6 & 3475 & 31.7 (26.0 to 38.2 ) & 41.8 \\
\hline \multirow[t]{3}{*}{ All } & Men & 1639 & 59.2 (48.0 to 72.2 ) & 78.9 & 2197 & 47.8 (39.1 to 57.9$)$ & 63.3 & 2766 & $32.9(26.5$ to 40.4$)$ & 43.5 \\
\hline & Women & 2954 & 50.1 (42.4 to 58.9 ) & 66.7 & 3512 & 38.2 (32.0 to 45.2$)$ & 51.0 & 3881 & 21.1 (16.8 to 26.2 ) & 28.2 \\
\hline & All & 4593 & 53.3 (46.9 to 60.5$)$ & 71.0 & 5709 & 41.9 (36.7 to 47.5$)$ & 55.7 & 6647 & $26.0(22.3$ to 30.2$)$ & 34.6 \\
\hline
\end{tabular}


Figure 1. Flow chart of the sample collection for the 13-year follow-up study of hearing impairment.

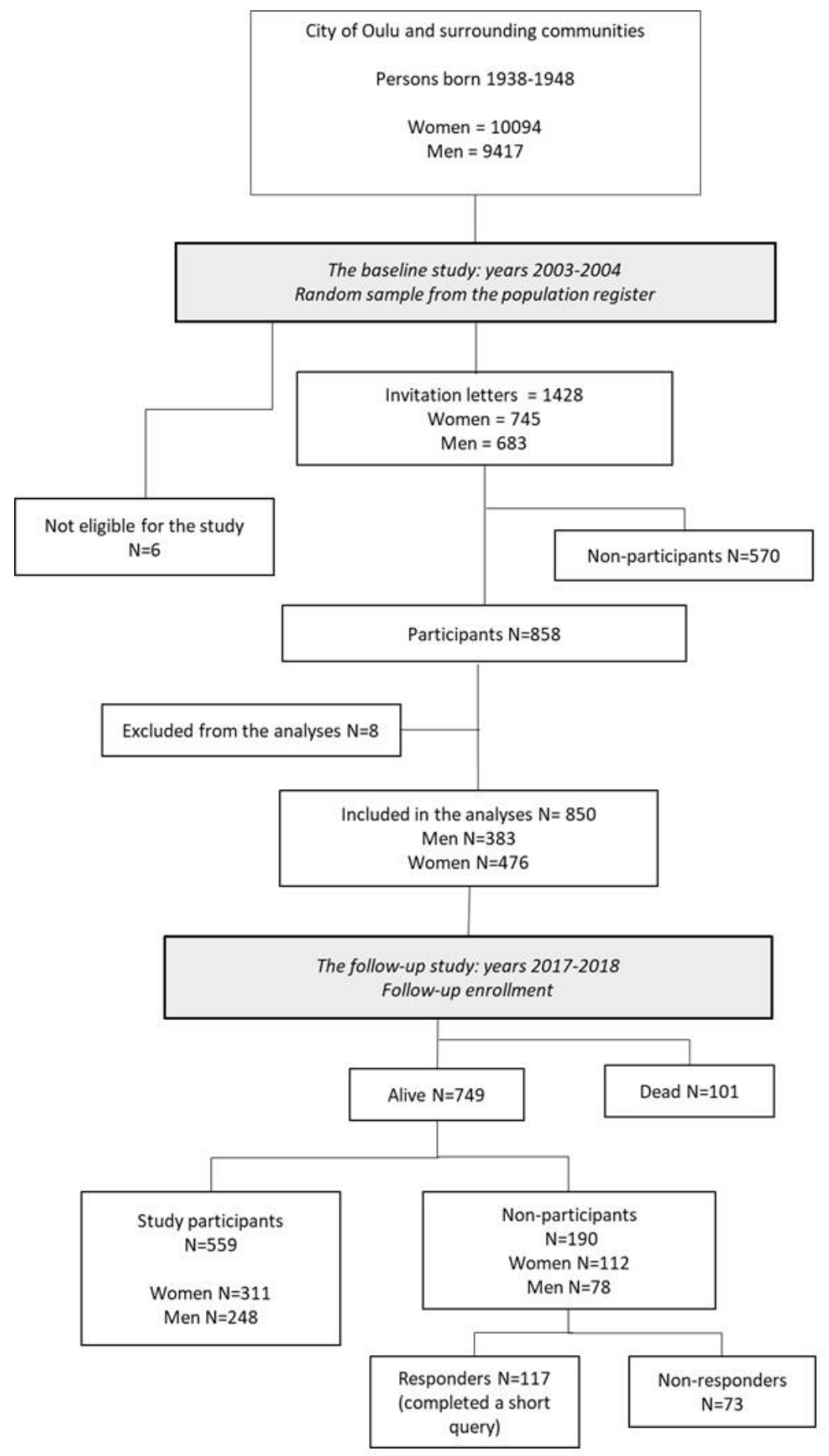

